\title{
Performance of deaf and hearing children on a short term memory task'
}

\begin{abstract}
Twenty four deaf children performed less well than a matched group of hearing children on a responsealternation memory task which was hypothesized to be facilitated by auditory imagery. Older Ss did better than younger. For all groups errors increased with increase in number of intervening trials between repetitions of the same stimulus.
\end{abstract}

\section{Problem}

Experiments have shown that deaf Ss are poorer than hearing Ss on tests of memory span when stimulus information is presented sequentially (Withrow, 1963; Olssen, 1962). This deficit has been related to the deaf's reduced experience in processing auditory information (which necessarily involves temporal sequences). Other studies have indicated that coding of information into auditory images is important for short-term memory of hearing Ss (Sperling, 1963; Waugh \& Norman, 1985; Wickelgren, 1965; Conrad, 1961). The present experiment assumed that congenitally deaf Ss would have less well developed systems of coding into auditory images and that any substitute systems they might have developed (e.g. kinesthetic imagery) would operate less efficiently than auditory imagery does for normal Ss. It was therefore hypothesized that performance of deaf Ss would be handicapped on a memory task which required no overt vocalization nor verbalization and in which the role of learning was minimized by the use of appropriate cues.

\section{Method}

The keeping-track-of-the-state-of-several-variables task (Yntema, 1963; Troxell \& Morin ${ }^{2}$ ) required $S$ to alternate responses to each of a set of colors. That is, each time a particular color was presented the $\mathrm{S}$ gave the response other than the one he had given the last time that color occurred. A maximum of four colors was used while the number of intervening trials between repetition of the same color was independently varied from zero to five. The two possible responses for each color were pictured objects whose names (not shown) began with the same initial sound (e.g., yellow-book and ball; blue-pie and pin). For example, a four-color series might have contained the sequence: yellow, red, blue, blue, green, red, yellow-in which the last yellow followed the preceding one by five intervening trials. If book were the response to the first yellow stimulus, then the child had to respond ball when yellow reappeared six trials later. Pictures were mounted on colored borders which matched the plastic stimulus card and cued $\mathrm{S}$ to the pair of suitable responses. Sets of such bordered pictures were displayed under clear plastic in a notebook. On each test trial, E presented a stimulus color and turned to a new page of pictures; $S$ responded by placing a cr yon mark over the selected picture.

Instructions to both deaf and hearing Ss were administered by gesture after $\mathrm{E}$ had determined that $\mathrm{S}$ knew the name for each picture. Ss were instructed in response alternation with a one-color and then a twocolor series of trials; the two test series utilized three and then four colors (designated the "task complexity" variable) which contained 44 and 58 test items respectively. Two groups of 12 children each with severe hearing impairment (ages: 8-9 $1 / 2$ and $101 / 2-121 / 2$ ) were matched with 24 public-school children with normal hearing on age, available IQ and parental occupation. All testing was conducted individually.

\section{Results}

Ss seemed to grasp the response alternation task with the exception of three members of both the deaf and hearing groups who were given additional practice with the one-color series. Nevertheless, on the threeand four-color test series, performance was generally poorer than had been anticipated on the basis of pretesting. Correlations between IQ and performance on the total test series were not significantly different from zero.

Table 1 shows percent correct responses for the three- and four-color series. A four-way, "mixed" (Type III) analysis of variance indicated that alternation scores for deaf Ss were lower than for hearing Ss $(p<.05)$ and that younger Ss performed less well than older ones $(p<.01)$. The interaction of deafness with age was not significant. Among "within-Ss" effects,

TABLE I Percent Correct Responses

\begin{tabular}{cccccc}
\multicolumn{2}{c}{$\begin{array}{c}\text { Intervening } \\
\text { Trials }\end{array}$} & \multicolumn{2}{c}{3 colors } & \multicolumn{2}{c}{4 colors } \\
\hline & & Deaf & Normal & Deaf & Normal \\
\hline \multirow{4}{*}{ Younger } & 0 & 71 & 71 & 64 & 80 \\
& 1 & 68 & 69 & 52 & 66 \\
& 2 & 56 & 65 & 61 & 65 \\
& 3 & 47 & 49 & 53 & 69 \\
& 5 & 44 & 43 & 47 & 57 \\
\hline \multirow{4}{*}{ Older } & 0 & 78 & 75 & 77 & 83 \\
& 1 & 83 & 78 & 61 & 79 \\
& 2 & 63 & 69 & 72 & 70 \\
& 3 & 56 & 64 & 61 & 66 \\
& 5 & 63 & 64 & 64 & 69 \\
\hline
\end{tabular}


errors increased with increase in number of trials intervening between successive presentations of the same stimulus $(p<.001)$. Hearing Ss performed better on the four-color series than on the three-color series while the opposite occurred for the deaf (deafness by complexity interaction; $p<.05)$. The interaction between task complexity and intervening intervals was significant $(p<.01)$; for the three color, less complex series better performance occurred at zero, one, and two intervening intervals while on the four color more complex series higher scores occurred for three and five intervening intervals.

Time required to complete each subtest was measured but there were no differences among groups. Vocalization, verbalization, or movement of the mouth (e.g. silent mouthing of words) was recorded. Although most Ss performed the task in silence as had been anticipated, more deaf than normal Ss engaged in vocal or mouth activity.

\section{Diseussion}

The lower scores of deaf Ss confirm the original hypothesis that deaf Ss would perform less well on this memory task. In retrospect it is recognized that this difference might have been even larger if it had been possible to eliminate certain differences in task conditions for the two groups (e.g. different hours for test scheduling, different available IQ tests, familiarity of $\mathrm{E}$ to one group). These influences may have facilitated experimental test performance of the deaf relative to that of the normals.

The significant interval by task complexity interaction may relate to the fact that when maximum number of intervals and colors are involved, the average rate at which a variable changes its state (i.e. the average rate of repetition of a particular color stimulus) is slower. Within the span of immediate memory, this less rapidly changing situation may evoke fewer confusions. The significant deafness by task complexity interaction may indicate differential influence on hearing Ss of either the effect mentioned in the preceding sentence or of additional practice (since the fourcolor series was always presented last).

These results support earlier findings that the deaf do not recall sequentially presented information as well as normal Ss and lend additional support to the assumption that coding of information into auditory images facilitates short-term memory。 A definitive test of this assumption requires additional exploration.

\section{References}

Conrad, R. Acoustic confusions in immediate memory. Brit. $J$. Psychol., 1964, 55, 75-84

Morin, R., \& Konick, A. Short-term memory and reaction time; keeping track of several variables. Psychon. Sci., 1964, 1, 325-326.

olssen, $\mathbf{J}$. The influence of language experience on memory span. Master's thesis, Catholic University of America, Washington, D. C., 1962

Sperling, G. A model for visual memory tasks. Hum. Factors, 1963 $5,19-30$

Waugh, N., \& Norman, D. Primary memory. Psychol. Rev., 1965, $72,89-105$.

Wickelgren, W. A. Acoustic similarity and intrusion errors in shortterm memory. J. exp. Psychol., 1965, 70, 102-108.

Withrow, F. Immediate recall by aphasic, deaf, and normally hearing children for visual forms presented simultaneously or sequentially in time. Doctoral Dissertation, Washington University, St. Louis, 1963

Yntema, D. B. Keeping track of several things at once. Hum. Factors, 1963, 5, 7-19.

\section{Notes}

1. Based on a thesis submitted by the first author in partial fulfillment of the requirements for a M.A. degree, Washington University, August, 1965. This investigation was supported in part by a National Institute of Nervous Diseases and Blindness Program-Project NB 03856, U.S. Department of Health, Education, and Welfare. 2. Personal communication. 